\title{
Deaf Gain e o ensino de Libras como segunda língua: formando aprendizes visuais
}

\author{
Carolina Ferreira Pêgo ${ }^{1}$ \\ Andre Ribeiro Reichert ${ }^{2}$ \\ Luiz Daniel Rodrigues Dinarte ${ }^{3}$
}

\section{Resumo}

Com a oficialização da Libras como a língua da comunidade surda brasileira pela lei 10.436/2002, e o decreto 5.626/2005, colocando essa língua no currículo de cursos de graduação, especificamente cursos de Licenciatura e fonoaudiologia, essa língua de modalidade visuo-espacial passou a receber mais atenção dos pesquisadores, especialmente da linguística aplicada. Observar a prática do ensino dessa língua em sala de aula, adotar a postura de professor-pesquisador, trazer à tona os percalços que os docentes encontram no ensino e aprendizagem; estes tornaram-se aspectos importantes a serem considerados nesse contexto.

Palavras-chave: Deaf Gain. Ensino de Libras. Experiência visual.

${ }^{1}$ Mestre em Linguística/UnB. Professora da UFSC.

2 Doutor em Linguística Aplicada/Unisinos. Professor da UFSC.

3 Mestre em Educação/UFRGS. Tradutor e Intérprete de Libras da UFRGS. 


\begin{abstract}
With the formalization of Libras (Brazilian Sign Language) as the language of Brazilian deaf community by Law 10.436 / 2002 and Decree $5,626 / 2005$ putting the language in the curriculum of undergraduate courses, specifically Degree courses and speech therapy, this visuospatial modality of language began to receive more attention from researchers, especially of applied linguistics. To observe the practice of teaching that language in the classroom, take the teacher-researcher posture, bring out the mishaps that teachers are teaching and learning; these have become important aspects to be considered in this context.
\end{abstract}

Keywords: Deaf Gain. Libras teaching. Visual experience.

\title{
Introdução
}

O artigo tematiza a ideia de Deaf Gain a partir da prática docente e da divulgação da língua de sinais e da cultura surda. Entende-se que o ensino de Libras nas universidades brasileiras na última década fez com que os surdos tivessem um maior reconhecimento social, assim como a língua de sinais passou a ser o pivô de uma mudança drástica na forma como a surdez é vista pela sociedade. Ensinando e valorizando a língua de sinais, valoriza-se o sujeito surdo. Sendo assim, o desprestígio histórico dos surdos tem na docência a ancoragem de uma posição política determinante para a mudança social dessa comunidade. 


\section{Língua de sinais: da falta de sons às infinitas possibilidades de expressão do sinalizante}

Com a oficialização da Libras como a língua da comunidade surda brasileira pela lei 10.436/2002, e o decreto 5.626/2005, colocando essa língua no currículo de cursos de graduação, especificamente cursos de Licenciatura e fonoaudiologia, essa língua de modalidade visuo-espacial passou a receber mais atenção dos pesquisadores, especialmente da linguística aplicada. Observar a prática do ensino dessa língua em sala de aula, adotar a postura de professor-pesquisador, trazer à tona os percalços que os docentes encontram no ensino e aprendizagem; estes tornaram-se aspectos importantes a serem considerados nesse contexto.

Consideremos aqui, antes de adentrarmos a discussão do processo de ensino e aprendizagem de uma língua de sinais, a característica visuoespacial desta modalidade linguística e a discussão sobre a abordagem pedagógica e política ensejada pela sua presença no contexto da educação. O fato de os surdos terem "privação da audição" (termo que discutiremos no tópico adiante) exige que se comuniquem em uma forma que seja acessível e que lhes permitam expressar seus pensamentos, descrever ações, e outros objetivos que uma língua cumpre.

As línguas de sinais atendem perfeita e completamente a esses objetivos comunicativos e cognitivos. Possuem uma gramática espacial complexa e que demanda os mesmos níveis de processamento cognitivo de uma língua oral. Quadros \& Karnopp (2004) as definem como línguas naturais, à semelhança das línguas orais; por isso, para além da diferença de modalidade como marca distintiva, são as características universais da linguagem que lhes conferem a legitimidade cultural, política e acadêmica da mesma maneira que qualquer outra língua.

Pelo fato de ser uma língua visual, alguns estudiosos lançam um olhar para sua a característica icônica, porém, segundo Faulstich (2006), devemos considerar dois aspectos ao analisar o estatuto linguístico da 
língua de sinais: a forma e a construção mental. Castro Júnior (2011), explica as reflexões de Faulstich: "se a LSB for considerada icônica só por causa da sua forma, da figura, da representação visual do objeto, ela não é considerada uma língua”. Acrescenta ainda que, a autora defende que a Língua de sinais deve ter construção mental porque nenhuma língua é só forma, é também conteúdo. Conclui que: "se existe uma construção mental, se o sinal apresenta conteúdo, então, a língua de sinais, incluindo a LSB, constitui-se em uma língua", não obstante a "falta" de sons que a caracteriza.

\section{O ensino de língua de sinais como Segunda Língua: ensino que agrega cultura}

Para Saussure, a língua é uma forma de categorizar, organizar e interpretar o mundo. Sabemos que essa definição é limitada quando consideramos o aspecto cultural, social, antropológico, político, educacional e outras características que permeiam o fenômeno linguístico de um ser humano ao se comunicar com outro. No que tange aos surdos e às línguas de sinais, a sua forma de interpretar o mundo e de expressar sua compreensão do que vem a ser o mundo, essa comunidade, com sua maneira peculiar de comunicar e representar o mundo, certamente tem muito o que contribuir, fazer pensar e repensar a Linguística. Não a linguística das línguas de sinais, mas a Linguística Tradicional, campo de investigação em que as línguas orais passam a encontrar suas limitações frente às outras possibilidades de análise que as línguas visuo-espaciais oferecem.

$\mathrm{Na}$ esteira dessas reversões conceituais, entendemos que o próprio imaginário sobre o surdo e os conceitos que amparam a determinação de seu lugar social, sofre uma total reversão. Entendemos que a própria ideia de normalidade passa a ser problematizada a partir dessa reversão 
de lugares sociais e do estatuto linguístico e científico da língua de sinais, assim como as noções de limitação e de deficiência, que são espectros que rondam a comunidade surda.

Um exemplo claro, no contexto de ensino de Libras como segunda língua - nos cursos superiores de licenciatura, em que a disciplina Libras é obrigatória - há um choque cultural quando esta é ministrada por um professor surdo. Há sempre a indagação, pelos alunos ouvintes: o que um surdo pode me ensinar? Como o conteúdo vai ser ministrado? O professor conseguirá fazer os alunos aprenderem o que deve ser aprendido? Thoma (2004, p. 57) afirma que: "A inversão epistemológica da anormalidade apontada pelos surdos consiste em fazer do corpo normal ouvinte o problema e aparece, por exemplo, em situações como a de pais e mães surdos/as que preferem gerar filhos/as também surdos/as."

Ou seja, como possibilidade de acesso natural e inconteste à linguagem e à cultura, existe inversão no sentido de ter como premissa a aceitação e o desejo da língua de sinais como forma legítima de comunicação. Um alargamento dos limites da normalidade ouvinte se produz, e não é sem surpresa que os ouvintes veem a preferência dos surdos em gerar filhos igualmente surdos. Por outro lado, os surdos encaram este desejo como algo absolutamente aceitável, uma vez que o que é normal para o surdo é que a comunicação e o pensamento sejam produzidos e acessados através de uma língua visuo-espacial.

No nosso caso, entendemos que a anormalidade seria tratar a língua como algo puramente visual, algo que se afasta daquilo que os alunos ouvintes estão habituados em termos da abordagem pedagógica das línguas e da língua materna, incluindo a sua própria. Em outras palavras, para sair do registro do exotismo da diferença de modalidade e da estetização de uma forma de comunicação, é preciso avançar na investigação linguística e cultural, de maneira a legitimar a língua de sinais como um sistema de comunicação tão rico e completo quanto qualquer língua oral. 
Trata-se de um conteúdo não relacionado com a oralidade, mas com a visualidade, apesar de se permanecer no escopo do pensamento, da expressão, da leitura, etc. Sinais, leitura, registro, visualidade e expressão, apesar de vivermos academicamente mergulhados em textos escritos: como esta mudança é recebida pelos alunos ouvintes?

Aprender sobre o que pode o corpo falante, como transpor o sentido para uma língua que não utiliza do recurso sonoro para construir seus enunciados; quais os impasses e possibilidades que as buscas pela adaptação à nova realidade linguística por parte dos ouvintes podem contribuir para o ensino da língua de sinais e sua consagração como uma língua legítima? Como questionou o filósofo Spinoza (2007), o corpo, longe de ser determinado por uma dimensão transcendente da razão e, portanto, partícipe do pensamento paralelamente à mente, o que pode fazer e ensejar no que tange à linguagem?

Alguns equívocos e desatenções dos alunos que chegam à disciplina de Libras são no sentido de considerar a língua de sinais como uma técnica passível de rápido aprendizado e domínio. Como se fosse um código, como o Braille, que um curso de poucos meses pode prover ao aluno o seu domínio, é comum que estes se surpreendam (e até mesmo se decepcionem) com o fato de que suas concepções estão equivocadas. Ao descobrir que a questão dos surdos envolve uma língua, uma cultura, uma questão identitária, os alunos despertam para uma troca efetiva, uma experiência diversa do que estão acostumados, pois se colocam em uma situação de aprendizagem para além de um conteúdo, mas todas as pressuposições que circundam a aparentemente singela "linguagem" (termo largamente empregado para se referir às línguas de sinais) acabam sendo mobilizados. Aí é que se pode pensar em um choque cultural e uma experiência de alteridade.

Muitos professores surdos não atentam ao caráter cultural e político contido nas apresentações das diferenças entre as línguas em sala de aula. Provavelmente por estarem imersos em uma cultura, ou mesmo por não 
terem tido contato com uma discussão mais crítica em relação à língua e seus efeitos na recepção desta pela cultura majoritária, muitos professores ainda se detêm no aprendizado dos sinais em termos de um aprendizado positivo e restrito ao domínio de um "saber" sobre a língua. Para além disso, entendemos que tal processo constitui-se em uma (re)construção de conceitos do que é língua, do que é o surdo, e de que essa modalidade linguística, sim, contribui nos processos cognitivos do aluno ouvinte, na medida que muda a maneira de absorver o conteúdo linguístico e cultural.

O ensino de Libras como L2 deve ser colocado em termos de elaboração do saber do professor surdo como experiência subjetiva válida no contexto da formação intelectual do professor. Um saber que não se tinha notícia até pouco tempo e que chega à formação acadêmica justamente pelas mãos dos professores surdos, e que, para além de um saber acadêmico, amplia a noção de língua, de comunicação e as noções sobre o que significa ser surdo. Ensinando sua língua e sua cultura, os professores surdos agregam ao rol de saberes válidos para a docência o saber de uma experiência visual da língua.

(...) los saberes experienciales surgen como núcleo vital del saber docente, núcleo a partir del cual los profesores tratan de transformar sus relaciones de carácter exterior con los saberes en relaciones de carácter interior con su propia práctica. En este sentido, los saberes experienciales no son saberes como los demás; están formados, en cambio, por todos los demás, pero traducido, pulidos y sometidos a las certezas construidas en la práctica y en la experiencia. (TARDIF, 2004, p. 41)

\section{Deaf Gain: Ser Surdo e a Língua de Sinais como ganhos adicionais na formação humana: do neurológico ao social-antropológico}

Da estrutura visual da língua de sinais surge uma curiosa relação entre a influência da modalidade visual e o fato de que esse componente 
visual tem muito o que contribuir para a comunidade ouvinte usuária de uma língua oral-auditiva. Isso nos leva a rever os conceitos de normalidade, não apenas na aceitação ou na "tolerância" em relação às pessoas surdas, mas no sentido de ampliar a própria noção de expressão, de escrita, de registro, ao possibilitar que o aluno transite por diferentes modalidades linguísticas.

Os ouvintes possuem essa recorrente curiosidade sobre os cinco sentidos que o ser humano possui e o que ocorre com a privação de um deles: os sentidos restantes são sobrecarregados ou de certa forma se tornam "super sentidos"? Para elucidar essa questão no que se refere à surdez, um estudo comparou o processamento visual de surdos e ouvintes, desde sua base neurorreceptiva até a interpretação cognitiva.

Bavelier, Dye and Houser (2006) relatam que as mudanças não são, contudo, generalizadas, mas são seletivas, limitando, como propomos, a esses aspectos da visão que são exigidos e normalmente beneficiam da convergência auditiva-visual. As alterações comportamentais são acompanhadas por uma reorganização das áreas multissensoriais, variando de córtex de ordem superior para as áreas corticais iniciais, destacando interações intermodais como uma característica fundamental da organização do cérebro e processamento cognitivo.

Quando liberada das concepções tradicionais, a surdez é vista a partir da necessidade de mudar a distribuição espacial da atenção de modo a que a atenção para o campo visual periférico, mas não o campo visual central, é aumentado. Bases neurais associadas revelam uma reorganização generalizada de córtices de associação mais elevadas, para córtices sensoriais iniciais. Uma característica comum encontrada em todas as áreas reorganizados é sua organização multimodal fundamentais, reforçando visões recentes sobre o papel da integração multimodal em todas as fases do processamento cognitivo.

O conceito de normalidade invadiu o conceito de surdo como algo a ser reconstruído: reenquadrada, a noção de normalidade não deixa 
de persistir, embora ganhe novas acepções e níveis de tolerância quanto aos seus limites. Não é que o surdo passe a ser considerado "normal", e nem a extensão da normalidade aos sujeitos surdos pode ser comemorada. Foucault (2001) entende que a anormalidade é digerida pela história através de variações discursivas em relação ao anormal. Ou seja, o que era anormal há tempos atrás não passa à normalidade, mas as formas de observar, estudar, descrever e categorizar o anormal variam conforme as necessidades atuais de gestão do saber e do poder sobre os corpos. Nesse sentido, nos restaria pensar a surdez e a língua de sinais naquilo que possuem de ganho, de reversão, de agudeza conceitual e não em termos de passividade em relação à tolerância e aceitação dos ouvintes em relação aos surdos.

"Deaf-Gain" é literalmente "Ganho surdo", ou seja, algo a mais que os surdos têm e os ouvintes não, algo de que os ouvintes podem se beneficiar na experiência da maneira surda de perceber o mundo. Achamos esta discussão bem fascinante, do ponto de vista da teoria de aprendizagem, de filosofia da percepção, linguística, etc. Por um lado, pensamos que a língua de sinais segue os princípios de funcionamento de todas as línguas, ou seja: a forma segue a função. Por outro lado, a língua visual é menos abstrata que a língua oral, pois a codificação auditiva é muito mais distante do referente extralinguístico que a codificação visual.

Deaf-gain é definido como um "reenquadramento de surdo, como uma forma de diversidade sensorial e cognitiva que tem o potencial de contribuir para o bem maior da humanidade." (DSDJ, p. 1). O termo é cunhado por Aaron Williamson de U.K e está disponível no site http:// dsdj.gallaudet.edu/, um periódico eletrônico da Universidade de Gallaudet que traz textos em língua de sinais. O termo Deaf-Gain (Visao Surda) reflete a particularidade da Visão Surda, ao fato de que tal característica exclusiva dos surdos tem muito o que a acrescentar à humanidade. Seus olhos surdos são ganhos positivos e não negativos como têm abordado diversas literaturas. 
A literatura que aborda o termo Deaf-Gain é escassa, enquanto aquela que concentra em observar e descrever com termos "surdez", "audiçao limitada", é ampla. O trabalho objetiva aprofundar no paradigma da ciência cognitiva, porém com a ótica de que o surdo tem a sua Visão Surda, transformando o paradigma tradicional que aborda a surdez de forma negativa.

Todos somos dotados de cinco sentidos: visão, audição, tato, paladar e olfato. O surdo, com um sentido a menos, teria um dos restantes mais desenvolvido, ou mais aprimorado? O nervo óptico, na sua base, tem a função de percepção de formas, movimentos, enquanto sua conexão cerebral, onde se localiza a região responsável pela tradução dos impulsos recebidos (língua de sinais, intérprete, etc).

Desde os anos 80, pesquisas foram feitas e verificaram que as reaçoes visuais de ouvintes e surdos eram bem semelhantes, ou seja, a base do nervo ótico era estimulado e respondia de forma igual. Já pesquisas abordando a conexão do nervo óptico com o cérebro, nessa região mais superior, algumas demonstram que os ouvintes e surdos têm reações e traduções semelhantes.

Assim, o conceito de Deaf Gain nos leva a uma mudança no paradigma na ciência cognitiva sob a ótica de um surdo. Outras pesquisas nessa área revelaram algumas diferenças, como por exemplo, nos surdos, o campo visual era maior e respondia mais rápido aos estímulos periféricos.

Uma pesquisa comparou quatro grupos: surdos filhos de pais surdos, CODA's, surdos oralizados e ouvintes que nao sabiam Língua de Sinais. A percepção visual de indivíduos surdos, sendo ou não sinalizantes nativos, era maior que dos codas e ouvintes que não sabiam língua de sinais. Conclui-se que a diminuição do sentido da audição traz aumento de campo visual. Pesquisas utilizando tomografias revelaram maior ativação parietal em surdos do que em ouvintes. Ao contrario do que muitos pensam, o surdo e o ouvinte possuem desenvolvimento mental-cognitivo com sutis diferenças. 
A pergunta que se faz aqui é: o aumento do campo visual dos surdos está relacionado com a aprendizagem visual e Ganho Surdo (Visao Surda?)? E qual será nossa posição em relação a este tipo de investigação? Quais as finalidades de defender o Ganho Surdo em termos políticos, pedagógicos e qual a ética envolvida nessa abordagem? Acreditamos que o Ganho Surdo não pode ser estabelecido como solução pedagógica, mas como demonstração da fragilidade das instituições contemporâneas de fazer com que a ciência positiva determinasse as capacidades dos sujeitos surdos, e mesmo o ensino da língua de sinais não pode ser visto como o espaço de reconstrução da integridade do surdo. A presença da língua de sinais nas escolas e universidades também irá institucionalizar saberes e poderes, mas as fraturas causadas pela suas possibilidades criadoras e as novas dinâmicas sociais que possibilita irão demonstrar um ganho não somente para o surdo, mas para o funcionamento das relações em que está inserido.

Algumas pesquisas determinam a idade de 10 aos 13 anos como a época em que o surdo desenvolve seu campo visual (amplia). Antes dessa idade, a visão periférica e campo visual do surdo e ouvinte é igual, já a partir dos 10 anos, o surdo desenvolve muito mais esse campo que o ouvinte. Essa ampliação do campo visual é relevante para compreender não apenas a vantagem que o surdo possuiria visualmente, mas também, e fundamentalmente, a limitação que os ouvintes sofrem em relação à percepção visual. É importante assinalar que a aprendizagem visual da criança surda depende da persença de modelos surdos adultos, em que expõem de forma peculiar o seu conehcimento de mundo, facilmente assimilado por elas.

Futuras pesquisas poderão elucidar as estratégias utilizadas por pais surdos para ensinar seus filhos surdos, estudando-as será possivel ensinar aos pais ouvintes para que adotem no seu cotidiano com seus filhos surdos. 
Desde a sua criação, o campo de Estudos Surdos tem constantemente desafiado concepções de normalidade (Bauman, 2008). Dentro deste contexto, de uma distribuição normal das populações humanas, o conceito de deficiência emergiu. A sociedade interpreta as pessoas com deficiência como discrepantes, como anomalias estatísticas que precisam ser elevada à normalidade. É esta interpretação que subjaz longa luta das pessoas surdas com o "normal". O quadro de normalidade moldou as relações tensas da comunidade surda no campo da educação, com a profissão médica, e com a sociedade mainstream. Se estabeleceu uma estatística ideal - o perfeito "normal", a pessoa para a qual todas as pessoas surdas são exortadas a se parecer.

Agora voltaremos ao quadro Teoria para analisar esta questão de incentivar as pessoas surdas a tornar-se o "normal". É evidente a forma como certos pontos de vista são estimulados, enquanto outros são expressamente desencorajados.

Quadro teoria pode ser aplicada ao conceito de "surdos". A surdez tem sido vista como uma perda, uma ausência, um vazio, uma falta de audição. É praticamente impossível pensar em surdez, sem pensar em perda. E, no entanto, as pessoas surdas, muitas vezes, não consideram suas vidas como uma mera perda. Em vez disso, há algo presente na vida das pessoas surdas, algo total e completo. Eles veem suas vidas através de um quadro que é diametralmente oposta ao quadro de perda auditiva. Nós chamamos este quadro de oposição de Deaf Gain.

\section{Considerações finais}

Vimos o quanto o ensino de língua de sinais contribui para modificar a representação em relação aos surdos. Passa-se de uma visão clínica, fundamentada na falta, na deficiência e nas práticas de correção 
para um entendimento sócio antropológico, que modifica a noção que a sociedade construiu sobre o conceito de surdez.

O detalhamento das estruturas da língua de sinais, a partir das pesquisas em Linguística, instrumentalizam os professores no sentido de explorar cada vez mais as possibilidades da modalidade visuo-gestual. As mudanças no meio de recepção e produção exigidas pela língua de sinais dão aos surdos um ganho cultural, uma valorização e uma projeção social que os torna cada vez mais empoderados politicamente. Deaf Gain significa esse tornar positivo o ser surdo, libertando a surdez da estreiteza da visão clínica tradicional.

\section{Referências}

BAUMAN, H-D. L. Introduction: Listening to Deaf Studies. In: H-Dirksen L. Bauman (Org.), Open your eyes:Deaf studies talking (pp. 1-34). Minneapolis: University ofMinnesota, 2008.

FOUCAULT, Michel. Os anormais: curso no Collège de France (19741975). Tradução: Eduardo Brandão. - São Paulo: Martin, Fontes.2001.

PEREIRA, M.C.C. Aquisição da leitura e da escrita por crianças surdas. Anais do Congresso Surdez e Pós-Modernidade: Novos rumos para a educação brasileira. Rio de Janeiro: Instituto Nacional de Educação de Surdos - INES - , Divisão de Estudos e Pesquisas, 29-35.

SOUZA, M.R. \& Góes, M.C.R. O ensino para surdos na escola inclusiva: Considerações sobre o excludente contexto de inclusão. In: Scliar, C.B. (Org.). Atualidade da educação bilíngue para surdos. V.1. Porto Alegre: Mediação, p.163-187, 1999. 
SPINOZA, Benedictus de. Ethica/Ética. Edição bilíngue LatimPortuguês. Tradução e Notas de Tomaz Tadeu. Belo Horizonte: Autêntica, 2007.

SVARTHOLM, K. Aquisição de segunda língua por surdos. Revista Espaço, junho 1998, 38-45.

THOMA, Adriana da Silva. A inversão epistemológica da anormalidade surda na pedagogia do cinema. In: Adriana da Silva Thoma; Maura Corcini Lopes. (Org.). A invenção da surdez: cultura, alteridade, identidade e diferença no campo da educação. Santa Cruz do Sul (RS): EDUNISC, 2004, v., p. 56-69.

VEIGA-NETO, Alfredo. Foucault \& a educação. Belo Horizonte: Autêntica, 2007. 